\title{
Evaluating tourism development models for Bodrum peninsula in Turkey
}

\author{
F. Gezici ${ }^{1}$, A. Y. Gül ${ }^{2}$ \& E. Alkay ${ }^{1}$ \\ ${ }^{1}$ Department of Urban and Regional Planning, \\ Istanbul Technical University, Turkey \\ ${ }^{2}$ Department of Urban and Regional Planning, \\ Yildiz Technical University, Turkey
}

\begin{abstract}
Significant destination areas in Mediterranean countries have faced the problems of mass tourism near the coastal areas and as a declining process. In addition, planning coastal regions, alternative tourism approaches and increasing quality have become the main strategies for the solutions. The development process of tourism in the Bodrum peninsula as one of the significant coastal destinations in Turkey contains certain threats on the sustainability of tourism. Misleading marketing, overcoming thresholds of development in the peninsula and encouraging construction along the coast impose threats for the future of tourism in Bodrum.

In this paper, the impacts of tourism on different dimensions such as the identity of the region, the natural-cultural environment, its social and economic structure and the factors that constitute a threat for the sustainability of tourism in Bodrum will be discussed. Secondly, the principal component analysis is applied in order to put forward the impact of defined variables on development in Bodrum. Different components are discussed for the evaluation of different development models related to impact of the variables. The results point out the threats on natural and cultural values and identity, and further on the deficient contribution to the local economy.
\end{abstract}

Keywords: tourism, development, principal component analysis, Bodrum peninsula. 


\section{Introduction}

Significant impacts of coastal mass tourism such as dense construction, land speculation and environmental pollution have appeared especially in the main destinations of the Mediterranean basin. While these areas have deteriorated, new destinations have emerged and the share of Mediterranean destinations in the market has been diminishing. However coastal tourism areas are always attractive with their advantages of climate and the triangle of "sea-sun-sand". It is neccessary to think about the future of coastal destinations in order to sustain the significant contribution of tourism to the local economy and to take its place in a competitive market. Furthermore, there has been a common assumption that if the natural, historical and cultural environment cannot be protected, there can be no expectations for sustainability in destination areas. If there is planned development, there will be a reduction in the loss of natural resources in terms of quantity and quality. However, tourism activities provide an opportunity to beautify the local environment and maintain its built assets in place of other economic activities [1].

There have been several studies focusing on the sustainability of tourism, planning efforts on coastal regions, the monitoring of the development, accelerating the transformation process, developing alternative tourism approaches and improving the quality, and these have become the main strategies in order to redefine the image of the coastal destinations facing these problems [2-8].

According to the results of Gezici's [9] analysis on coastal and inland cases in Turkey, coastal destination areas have encountered more pressure and more intensive environmental problems. Therefore, the Bodrum peninsula has been chosen as a popular coastal destination with its problems and threats for future tourism. Firstly the main hypotheses focus on the impacts of tourism and the threshold of tourism is examined. Secondly, the relationship between tourism and development by using principal component analysis is put forward. Further, development models are discussed based on the results of the principal component analysis.

The next section will display a brief explanation about tourism development in the Bodrum peninsula. The third section will put forward the research methodology and the findings of the analysis. The conclusion will discuss the results and strategies for the future tourism development in the Bodrum peninsula.

\section{Development process of tourism in the Bodrum peninsula}

In Turkey, tourism investments have noticeably increased since the enactment of the Law for Encouragement of Tourism in 1982. Increasingly investment incentives have been also oriented on coastal regions, especially the Mediterranean and Aegean coasts that already have adequate infrastructure and potential for tourism development, by encouraging large-scale tourism complexes. Coastal provinces get a very high share of Turkish tourism, shown 
by the statistics of foreign tourists' nights spent (95.96\% of foreign tourists spend a night in a coastal province). $55.10 \%$ of the nights spent in coastal provinces take place in the Mediterranean, while $25.39 \%$ take place in the Aegean region [10]. Bodrum is one of the main tourism destination districts of Muğla province and is located on the southern coast of the Aegean region (see Figure 1).

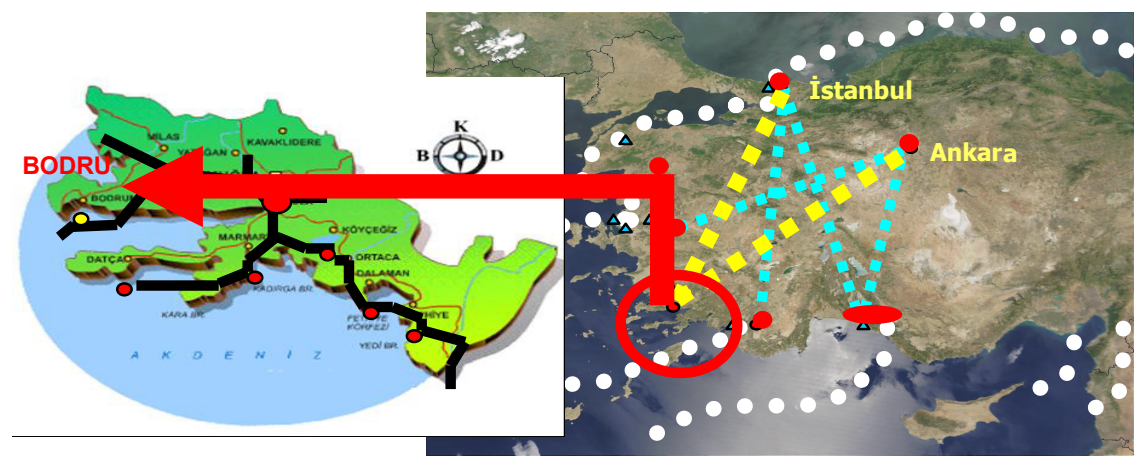

Figure 1: Location of Bodrum in Turkey.

Assuming the first ranking city, Antalya, as 100, Bodrum-a district of Muğlareceives values of 30 and 28 for tourist arrivals and nights spent, respectively. Foreign tourists make up $63.42 \%$ and $81.54 \%$ of the tourist arrivals and nights spent in Muğla. Further, Muğla has the largest share among all coastal provinces in terms of domestic tourists. Bodrum's foreign tourist share is $12.60 \%$ and its domestic tourist share is $15.25 \%$ in terms of tourist arrivals among the coastal districts [11].

The Law for Encouragement of Tourism in 1982 and the construction of the Dalaman airport have accelerated tourism activities in Bodrum, which previously had been a fishermen's village. In 1998, the opening of the Bodrum-Milas airport, $40 \mathrm{~km}$. from the district center of Bodrum, provided easier accessibility to Bodrum from big cities in Turkey, even for weekends. Hence, Bodrum has taken its place in the tourism market as an entertainment holiday center. This image of the settlement has initiated a process of evolution in urban space. The pressure towards the land has increased in the Bodrum peninsula within this process.

The development process and tendencies of tourism in the Bodrum peninsula as one of the significant coastal destination of Turkey put forward certain threats on the sustainability of tourism. Misleading marketing, overcoming thresholds of development in the peninsula and encouraging construction along the coast impose threats for the future of tourism in Bodrum. The research is constructed based on these assumptions in order to put forward the impacts of tourism and the factors, which influence tourism development. 


\section{Research methodology and findings}

\subsection{Research methodology}

Data are obtained from the questionnaire conducted in 2004 as part of the research project in the Bodrum peninsula called "Testing Sustainable Tourism Criteria with Alternative Development Models in Tourism Planning of Coastal Provinces".

Firstly, the main hypotheses, which focus on the impacts and thresholds of tourism, are tested. Secondly, the principal component analysis is applied to determine the socio-economic development level related to tourism development. The variables are chosen from the questionnaire of the research (359 questionnaires). Twenty-five variables are determined with respect to the purpose of the paper, including natural and cultural environment, accessibility, demographic and social environment, and the economic structure such as urban macro-economy, urban values and economic welfare.

The principal component analysis is a statistical technique that analyses the set of variables linearly in horizontal components and defines independent dimensions of the data in terms of observed variables. This technique is adopted because it lends itself to abolishing the dependent structure between variables, to separately showing the dimensions that affect changeability in a data set. Before the application of the principal component analysis technique, variables that have different units of measurement and size were standardized.

\subsection{Findings}

\subsubsection{The hypotheses to test the impacts and the thresholds of tourism}

$\mathrm{H}_{\text {TYE1}}$ : Tourism is developed based on original characteristics of Bodrum.

$\mathrm{H}_{\text {TYE2}}$ : There is a correlation between tourism development and conservation of natural and cultural values.

$\mathrm{H}_{\mathrm{TYE} 3}$ : There is a correlation between tourism development and changes in social structure.

$\mathrm{H}_{\text {TYE4}}$ : There is a correlation between tourism development and changes in economic structure.

$\mathrm{H}_{\mathrm{TED} 1}$ : There are significant threats on sustainability of tourism in Bodrum.

The hypotheses are tested using the results of 359 questionnaires from the residents based on their perceptions. First a hypothesis is tested by looking at the correlation between the original identity and the tourism identity of the Bodrum peninsula and the results point out the correlation between two variables. Even though "sea", "blue" and "entertainment" are the main and the similar definitions for both original identity and tourism identity of Bodrum, there are evidences that original identity is not involved in the promotion of Bodrum as it is expected. Therefore the image of "entertainment" takes priority in marketing tourism in Bodrum in place of its cultural and archeological assets. 
For the second hypothesis, there is not any significant correlation. Therefore the natural and cultural values are not utilized in order to enhance tourism development in Bodrum. For the third hypothesis, no evidence has been obtained that there are tourism development changes in the social structure. For the fourth hypothesis, some variables of economic structure such as "tourism-dependent rise in income" and "economic contribution by summer houses" point out a positive correlation between tourism development and the economic structure.

Thus, the results of testing the main impacts of tourism put forward that the residents perceive the economic impacts of tourism to be more favorable and significant than others. Further, attention should be directed to the strategies in order to improve the image of Bodrum, focusing on original identities and natural and cultural values.

Table 1: The variables in the analysis of the impact of tourism on socioeconomic development in Bodrum.

\begin{tabular}{|c|c|c|}
\hline VARIABLES & & $\begin{array}{l}\text { CONDITIONS REFLECTED BY } \\
\text { VARIABLES }\end{array}$ \\
\hline COAST & Natural features of the coast & \multirow{4}{*}{ Natural/Cultural Values } \\
\hline ARCHLOGY & Archeological areas & \\
\hline WTRRCHLGY & Underwater archeology & \\
\hline ARCHIT & Originality of architecture & \\
\hline AGE & Age & \multirow{5}{*}{ Demographic and social structure } \\
\hline EDUCATION & Education level & \\
\hline LANGUAGE & Speaking of a foreign language & \\
\hline BRTHPLC & Place of birth & \\
\hline WHEN & Date of settling in Bodrum & \\
\hline INCOME & Income level & \multirow{7}{*}{ Urban macro-economics } \\
\hline WRKNGPPL & Number of working people in the family & \\
\hline SECTOR & Sectoral distribution of workers & \\
\hline AGRTRZM & Tourism-dependent economic boom in agriculture & \\
\hline CONSTTRZM & Tourism-dependent economic boom in construction sector & \\
\hline SCNDHS & Economic contribution by summer houses & \\
\hline TRZFCLTS & Contribution of tourism facilities to Bodrum's development & \\
\hline LANDOW & Land ownership & \multirow{5}{*}{ Rise in urban values } \\
\hline ALLOCAT & Allocation of land to urban functions & \\
\hline FUNCTION & Type of allocated urban functions & \\
\hline HPRICES & Tourism-dependent rise in housing prices & \\
\hline LVALUES & Tourism-dependent rise in land values & \\
\hline TRZEMPL & Tourism-dependent rise in employment opportunities & \multirow[t]{2}{*}{ Welfare } \\
\hline TRZINCOME & Tourism-dependent rise in income & \\
\hline ACCESLTY & Accessibility to Bodrum & \multirow[t]{2}{*}{ Accessibility } \\
\hline ACTYINBODRUM & Accessibility in the Bodrum peninsula & \\
\hline
\end{tabular}


In order to test the thresholds of tourism, looking at the relationship between the threats of sustainability of tourism in Bodrum and the priority and important objects for its tourism development, a significant correlation is found. It means that the significant components of tourism in Bodrum are facing the threats as well. The main threats are sea pollution, an increasingly built up environment, the loss of natural values, the deterioration of the coast line, the deterioration of archeological areas, the increasing use of second homes, while sea-sun-sand, bays of the peninsula, the Bodrum Castle, the archeological assets and underwater archeology are defined as priority components for future tourism in Bodrum.

\subsubsection{The principal component analysis}

In the second step of the paper, the principal component analysis is applied to define the impact of tourism on the development level of Bodrum. Twenty-five variables are determined (see Table 1).

The statistical analysis employed a standardized data matrix of $359 \times 25$ (359 questionnaires-observations, 25 variables). The variances of principal components and their rate of explanation obtained upon analyses are given in Table 2. It indicates that 10 out of the 25 principal components have a variance greater than " 1 ".

Table 2: $\quad$ The principal component rates of variance and explanation.

\begin{tabular}{|c|c|c|c|}
\hline Component & Total & $\%$ of Variance & Cumulative \% \\
\hline 1 & 2,47 & 9,89 & 9,89 \\
\hline 2 & 2,38 & 9,50 & 19,39 \\
\hline 3 & 1,87 & 7,49 & 26,88 \\
\hline 4 & 1,52 & 6,08 & 32,95 \\
\hline 5 & 1,38 & 5,53 & 38,49 \\
\hline 6 & 1,32 & 5,27 & 43,76 \\
\hline 7 & 1,23 & 4,92 & 48,67 \\
\hline 8 & 1,18 & 4,73 & 53,40 \\
\hline 9 & 1,05 & 4,22 & 57,62 \\
\hline 10 & 1,00 & 4,01 & 61,63 \\
\hline 11 & 0,94 & 3,76 & 65,39 \\
\hline 12 & 0,91 & 3,66 & 69,04 \\
\hline 13 & 0,80 & 3,22 & 72,26 \\
\hline 14 & 0,78 & 3,12 & 75,39 \\
\hline 15 & 0,76 & 3,02 & 78,41 \\
\hline 16 & 0,72 & 2,88 & 81,29 \\
\hline 17 & 0,67 & 2,67 & 83,96 \\
\hline 18 & 0,65 & 2,59 & 86,56 \\
\hline 19 & 0,60 & 2,41 & 88,96 \\
\hline 20 & 0,59 & 2,37 & 91,34 \\
\hline 21 & 0,53 & 2,13 & 93,47 \\
\hline 22 & 0,50 & 2,01 & 95,48 \\
\hline 23 & 0,46 & 1,85 & 97,33 \\
\hline 24 & 0,41 & 1,65 & 98,98 \\
\hline 25 & 0,25 & 1,02 & 100,00 \\
\hline
\end{tabular}


The columns of the principal component matrices in Table 3 show the weight of each variable in the principal components. Their rows reflect the weight of a variable in different principal components.

Table 3: $\quad$ The principal component weights.

\begin{tabular}{|c|c|c|c|c|c|c|c|c|c|c|}
\hline & \multicolumn{10}{|c|}{ Components } \\
\hline & 1 & 2 & 3 & 4 & 5 & 6 & 7 & 8 & 9 & 10 \\
\hline AGE & $-0,09$ & 0,13 & $-0,02$ & 0,17 & 0,37 & 0,09 & 0,01 & 0,15 & $-0,04$ & 0,08 \\
\hline EDUCATION & 0,19 & $-0,22$ & 0,09 & 0,12 & $-0,16$ & 0,08 & 0,03 & $-0,13$ & $-0,04$ & 0,03 \\
\hline LANGUAGE & $-0,17$ & 0,20 & $-0,13$ & $-0,04$ & 0,16 & $-0,04$ & $-0,08$ & 0,23 & $-0,02$ & $-0,15$ \\
\hline BRTHPLC & $-0,09$ & 0,11 & 0,01 & 0,05 & $-0,13$ & $-0,31$ & $-0,15$ & $-0,16$ & 0,34 & 0,16 \\
\hline WHEN & 0,06 & $-0,16$ & $-0,04$ & 0,00 & 0,07 & 0,36 & 0,00 & 0,40 & 0,03 & 0,04 \\
\hline INCOME & 0,02 & $-0,05$ & 0,16 & $-0,14$ & 0,04 & 0,22 & 0,25 & $-0,21$ & $-0,03$ & 0,32 \\
\hline WRKNGPPL & $-0,05$ & $-0,02$ & 0,13 & $-0,09$ & $-0,10$ & 0,16 & $-0,35$ & $-0,14$ & $-0,08$ & 0,44 \\
\hline SECTOR & 0,04 & $-0,14$ & 0,09 & 0,07 & 0,02 & 0,08 & 0,27 & 0,33 & 0,44 & 0,06 \\
\hline LANDOW & 0,02 & $-0,10$ & $-0,37$ & 0,01 & $-0,07$ & 0,08 & $-0,07$ & $-0,09$ & 0,09 & $-0,06$ \\
\hline ALLOCAT & $-0,11$ & 0,12 & 0,34 & $-0,06$ & 0,10 & $-0,07$ & 0,14 & $-0,03$ & $-0,04$ & 0,06 \\
\hline FUNCTION & $-0,04$ & 0,08 & 0,29 & 0,02 & $-0,02$ & $-0,05$ & 0,07 & 0,24 & $-0,17$ & 0,02 \\
\hline HPRICES & 0,14 & 0,25 & $-0,06$ & $-0,14$ & $-0,31$ & 0,08 & 0,22 & 0,08 & $-0,05$ & 0,02 \\
\hline LVALUES & 0,15 & 0,25 & $-0,09$ & $-0,16$ & $-0,28$ & 0,08 & 0,19 & 0,09 & $-0,05$ & 0,14 \\
\hline TRZEMPL & 0,20 & 0,01 & 0,17 & $-0,05$ & 0,04 & $-0,18$ & $-0,12$ & $-0,01$ & $-0,05$ & $-0,42$ \\
\hline TRZINCOME & 0,22 & 0,00 & 0,05 & 0,04 & 0,00 & $-0,12$ & $-0,24$ & 0,07 & $-0,34$ & $-0,02$ \\
\hline AGRTRZM & 0,11 & $-0,05$ & $-0,02$ & $-0,17$ & 0,19 & $-0,32$ & 0,20 & $-0,08$ & 0,38 & 0,18 \\
\hline CONSTTRZM & 0,19 & 0,12 & 0,14 & 0,11 & $-0,02$ & 0,14 & $-0,23$ & 0,17 & 0,28 & $-0,15$ \\
\hline SCNDHS & 0,15 & 0,03 & $-0,11$ & $-0,09$ & 0,01 & $-0,27$ & $-0,14$ & 0,34 & 0,02 & 0,30 \\
\hline TRZFCLTS & 0,16 & 0,05 & $-0,06$ & $-0,06$ & 0,26 & 0,01 & $-0,24$ & $-0,06$ & 0,09 & 0,36 \\
\hline COAST & 0,09 & 0,03 & 0,03 & 0,44 & $-0,08$ & $-0,21$ & 0,20 & $-0,03$ & 0,03 & 0,04 \\
\hline ARCHLOGY & 0,12 & 0,10 & $-0,11$ & $-0,19$ & 0,32 & 0,08 & 0,25 & $-0,15$ & $-0,14$ & $-0,08$ \\
\hline WTRRCHLGY & 0,21 & 0,01 & $-0,01$ & 0,12 & 0,28 & $-0,01$ & 0,10 & $-0,19$ & $-0,16$ & $-0,03$ \\
\hline ARCHIT & $-0,02$ & 0,06 & $-0,12$ & 0,42 & 0,00 & $-0,01$ & 0,13 & 0,06 & $-0,26$ & 0,36 \\
\hline ACCESLTY & 0,09 & 0,18 & 0,09 & 0,11 & 0,11 & 0,29 & $-0,17$ & $-0,12$ & 0,28 & 0,02 \\
\hline ACTYINBODRUM & $-0,01$ & 0,17 & $-0,04$ & 0,19 & $-0,07$ & 0,20 & 0,00 & $-0,26$ & 0,22 & $-0,16$ \\
\hline
\end{tabular}

It is possible to obtain one development index for each component since the analysis is applied to the case of Bodrum. Therefore the index values of 10 components are calculated and ranked (Table 4). While 7 of them indicate the negative values, 3 of them indicate positive index values. The fifth principal component is differentiated from the others and indicates the highest value of development index. 
Table 4: Development index values based on the principal components.

\begin{tabular}{|l|l|}
\hline Components & Index values \\
\hline 5 & 0.6235 \\
\hline 4 & 02852 \\
\hline 9 & 0.2032 \\
\hline 8 & -0.0191 \\
\hline 1 & -0.2319 \\
\hline 7 & -0.2519 \\
\hline 10 & -0.2820 \\
\hline 6 & -0.3838 \\
\hline 3 & -0.3875 \\
\hline 2 & -0.6979 \\
\hline
\end{tabular}

In order to discuss different tourism development models in the Bodrum peninsula, two principal components (5 and 4), which have positive index values, are examined. The third one was not taken into account since the index values of the $4^{\text {th }}$ and $9^{\text {th }}$ components are close to each other. It is seen that in defining the impacts, some variables have effects in the positive and some in the negative direction.

Age is a significant variable for both principal components as a variable of demography. The demographic structure of Bodrum shows that $83 \%$ of the total population is an active population. Education and the speaking of a foreign language are the other variables, which have positive impacts on development level in different components (see Table 3).

Evaluating the $5^{\text {th }}$ principal component, archeology and underwater archeology have a positive impact on the development index, while coastal features and originality of architecture indicate a negative impact. Rapid development and intensity in the construction sector points out the threats to these natural and cultural values and significant tourism attractiveness of Bodrum. Therefore, the "tourism-dependent economic boom in the construction sector" has a negative impact on development. It might be defined as an artificial impact on the local economy. On the other hand, the "contribution of tourism facilities to development", a "tourism-dependent rise in employment opportunities", a "tourism-dependent economic boom in agriculture" and the "economic contribution by summer houses" have positive-oriented relations with the development index as variables of urban macro-economics and welfare. This result points out a development pattern with local involvement in the tourism sector. On the other hand, it is seen that variables that are deemed to reflect the rise in urban values such as "land ownership", a "tourism-dependent rise in housing prices", a "tourism-dependent rise in land values", and "allocation of land to urban functions" have a negative effect. Accessibility has a positive impact in terms of high accessibility to Bodrum, while indicating a negative impact in terms of accessibility problems within the Bodrum peninsula. These relations and impacts display the main factors which influence tourism 
development and socio-economic development in the case of Bodrum. Further, it points out the main threats and opportunities for future development models.

In the $4^{\text {th }}$ principal component, coastal features, originality of architecture and underwater archeology as the variables of natural and cultural values indicate a positive impact, while archeology has a negative impact. As the variables of urban macro-economics and welfare, the "contribution of tourism facilities to development", the "tourism-dependent rise in employment opportunities", the "tourism-dependent economic boom in agriculture" and the "economic contribution by summer houses" indicate a negative-oriented relation contrary to the $5^{\text {th }}$ principal component. On the other hand, the variables that are deemed to reflect the rise in urban values, such as a "tourism-dependent rise in housing prices", a "tourism-dependent rise in land values", and an "allocation of land to urban functions" have a negative effect on a development level parallel to the $5^{\text {th }}$ principal component. Accessibility has a positive impact for both Bodrum and within Bodrum. The relations between the variables and development index for the $4^{\text {th }}$ principal component emphasize the significant role of natural and cultural values such as coastal beauties and originality of architecture for tourism in the Bodrum peninsula. Therefore the protection and sustainability of these values has become inevitable. Moreover, it points out that archeological values are not involved in the tourism development process as had been expected. In this case, there is not any significant local involvement in the economy related to tourism development, and tourism activities do not revive the agricultural sector. Further, the construction sector indicates its dominancy in the local economy related to tourism development. Accessibility and tourism demand accelerate real estate dynamics in Bodrum.

After evaluating the results of the principal component analysis, it would be discussed on two type development models; the first one is relatively pointing out the threats on natural and cultural values and identity, and the second one is pointing out the deficient contribution to the local economy. However, both of them emphasize the relationship between tourism and land values as one of the main threats for the sustainability of tourism in Bodrum. Increasing land values lead to an appetite for natural resources such as coastal areas, forests and orange tree orchards, resulting in development permits on areas that should be preserved.

\section{Conclusion}

The problems of the coastal mass tourism destination areas in the Mediterranean Basin stimulate the tourism research to analyze the potential threats of significant destinations and to discuss the impacts of tourism. Furthermore, there have been efforts on developing strategies in order to change the destiny of these destinations. Bodrum is one of the popular destinations in Turkey, however major threats for the sustainability of tourism have appeared.

The main hypotheses put forward that the residents perceive the economic impacts of tourism more favorably than others. The main threats are defined as sea pollution, an increasing built-up environment, the loss of natural values, the 
deterioration of the coastal line, the deterioration of archeological areas, an increase in second homes. At the same time, the sea-sun-sand, the bays of the peninsula, the Bodrum Castle, archeological assets and underwater archeology are defined as priority components of future tourism in Bodrum.

Furthermore, the results of principal component analysis emphasize the increasing land values as one of the main threats for the sustainability of tourism in Bodrum. Increasing land values have been a reflection of continuity of demand and construction activities. Moreover, it makes the region more expensive. Based on the principal component analysis, development models of Bodrum emphasize the threats on natural and cultural values and the identity of the region, and the deficient contribution to the local economy.

Therefore, one of the main strategies should be to focus on misleading marketing and direct efforts to improve the image of Bodrum, concentrating on original identities and natural and cultural values. Diversity of tourism activities would help to improve the image of the region and, furthermore, to contribute to the local economy. Planning efforts should draw up the activities along the coast and create dissuasive steps against development which has been overwhelming the heart of the peninsula.

\section{References}

[1] Hunter, C. (1997), Sustainable Tourism as an Adaptive Paradigm. Annals of Tourism Research 24:857-867.

[2] Barke, M. and Towner, J. (2004) Learning From Experience? Progress Towards a Sustainable Future for Tourism in the Central and Eastern Andalucian Littoral, in Coastal Mass Tourism: Diversification and Sustainable Development in Southern Europe, Ed. B. Bramwell, Channel View Publication, Clevedon, 157-174.

[3] Garcia, G. M, Pollard, J. and Dominguez Rodriguez, R. (2004), The Planning and Practice of Coastal Zone Management in Southern Spain, in Coastal Mass Tourism: Diversification and Sustainable Development in Southern Europe, Ed. B. Bramwell, Channel View Publication, Clevedon, 201-219.

[4] Vera Rebollo, J. F. and Baidal, J. A. I. (2004), Measuring Sustainability in a Mass Tourist Destination: Pressures, Perceptions and Policy Responses in Torrevieja, Spain, in Coastal Mass Tourism: Diversification and Sustainable Development in Southern Europe, Ed. B. Bramwell, Channel View Publication, Clevedon, 176-199.

[5] Robledo, M. A. and J .Batle (2002) Re-planning for tourism in a Mature Destination: A Note on Mallorca, in Tourism in Western Europe, A Collection of case Histories., ed. By. R.Voase, Un. of Lincoln, CABI Pub.

[6] Agarwal, S. (2002) Restructuring Seaside Tourism: The Resort Lifecycle. Annals of Tourism Research, 29:25-55.

[7] Goodall, B. and M. Stabler. (2000) Environmental Standards and Performance Measurement in Tourism Destination Development, in 
Tourism and Sustainable Community Development, Eds. G. Richards and D. Hall, London: Routledge, 63-82.

[8] Marchena Gomez, M. J. and F. V. Rebollo (1995) Coastal Areas: Processes, Typologies and Prospects, in European Tourism, Regions, Spaces and Restructuring, Eds. A.Montanari ve A.M.Williams, John Wiley \& Sons.

[9] Gezici, F. (2006) Components of Sustainability: Two Cases from Turkey, Annals of Tourism Research, 33(2).

[10] Ministry of Culture and Tourism (Kültür ve Turizm Bakanlığı) (2003) Tourism Statistics, http://www.kulturturizm.gov.tr/

[11] Gezici, F., A. Y. Gül and Alkay, E. (2005) Concentration of Tourism Activities and Economic Sustainability of Tourism Facing the Threats: Case of Bodrum in Turkey, Theoretical Advances in Tourism Economics, CD-ROM, Evora. 